\title{
Intercommunity Medicine Partition, Peacekeeping and Public Health Cyprus 1975
}

\author{
Colonel R L Bell, \\ MRCS, LRCP, FFCM, MFOM, DPH, DIH, DTM\&H, L/RAMC \\ ${ }^{*}$ Commander Medical Services HQ South East District, Aldershot
}

"I have invented a new disease. It has first to be described. That is our way of patenting it and making it our own. Thenci makes me immortal".

\section{Introduction}

The title "Intercommunity Medicine" is coined to describe the strange tasks which fell to the lot of the Medical Services of UNFICYP in 1975, after the end of active hostilities between Greek and Turkish Cypriots the previous year. This paper gives a brief outline of the events leading up to the partition of the island and the ensuing need for an impartial medical service to deal with serious public health matters of pressing urgency, as well as carrying out humanitarian work in the aftermath of conflict. Some unusual miscellania are briefly recorded.

\section{The Background}

Much of Cyprus is poor. Writing of it in 1958 Tremayne summed up the effect of this poverty neatly when she wrote of the villagers of the Larnaca plain "They are not perhaps so very far down the scale of human misery, compared with what can be found in other countries; but they are at the bottom of it in the only country they know; and the fact that they are aware of this gives them inevitably a sore feeling, and a proneness to disaffection." This disaffection had for long made the relationship between Greek and Turk that of a marriage gone sour: hard words, insults and often blows, punctuated by counsel from the wise and not-so-wise, and by periods of uneasy peace and armed neutrality.

In 1963, only three years after the Republic of Cyprus came into being, serious and widespread intercommunal violence broke out, and UNFICYP was formed. During the subsequent decade this Force prevented serious violence from starting again and undoubtedly acted as a stabilizing influence. Thus, though inwardly seething, the island outwardly appeared to be calm. Turkish Cypriots tended to isolate themselves in sectors of the larger towns, and some fairly large enclaves in the

\footnotetext{
* Formerly Chief Medical Officer, United Nations Force in Cyprus (UNFICYP).
}

country were "no go" areas for Greek Cypriots; this boded no good for the future.

The coup which deposed Archbishop Makarios on July 1974, and the urgent and explicit expectatiog a Enosis with Greece provided Turkey with a pefferet excuse (some would say a perfect reason) for invađiog the island to safeguard the lives and interests of thet blood brothers. This she did only five days later who force which at its peak was computed to be 40 of strong, that is one soldier for every three Turisin Cypriot men, women and children.

\section{The Situation in 1975}

By early 1975 the island was partitioned by a bogder almost as real and seeming nearly as permanent as between East and West Germany. Both sides occupied defended positions on either side of the strip of n\& man's-land marking the Cease Fire Line which w\&s policed and superintended by UNFICYP.

To this major boundary must be added the islets of humanity which finished the war on the wrong side of about 11,000 Greek Cypriots in the Karpas Peninsula the extreme North East and about 16,000 Turkiş Cypriots in enclaves of various sizes throughout th South, the "unsurrendered villages", words reminisce of Northern Ireland. Both sides used these people political bargaining points.

This rigid partition introduced the Medical Service $\overrightarrow{\overrightarrow{\partial f}}$ UNFICYP to very considerable medical problems which it had not met before, at least not in significant quantit.. The Service was intended primarily to look after the Force: now it had to think of emergency care and evacuation of civilians, and civilian public health woak for which it had never been designed but with which coped without disgracing itself.

\section{UNFICYP: The Force and its Medical Service}

The composition of the Force varied from time to time. At the beginning of 1975 it comprised seven majofr units: two from Britain and one each from Austrta, 
Canada, Denmark, Finland and Sweden. Some of these units were full battalions with supporting troops, others only two companies strong, but each had an RMO and medical establishment. Logistic support and hospital care for the Force were provided by the British Sovereign Bases. The Chief Medical Officer (CMO) and Force Health Inspector (FHI), a qualified Environmental Health Warrant Officer, were both in the British Regular Army.

\section{Public Health - General}

In making an initial appreciation of the situation it was clear that the island faced grave perils from the complete dichotomy and partial collapse of a Public Health Service which had never been funded over-generously. The plight of the refugees in their camps in the South, the beleaguered hostages in their enclaves, and the huge efforts put into succouring them seemed to have pushed any premonition of the possibility of pestilence into the background. It was resolved to give Environmental Health its rightful place in the list of priorities. Before this could be achieved some means of coercing the two factions to cooperate in health matters needed to be found, and it was not to be very long before the opportunity came.

\section{Neisseria meningitidis Meningitis}

The removal of a rural community to a crowded camp, defended ghetto or any place of concentration favours epidemics of various kinds, one of the most unwelcome being meningitis. Sporadic reports of this disease among Greek hostages in the North were never confirmed until a sharp outbreak occurred in the Morphou area.

Getting information from the Turkish authorities was never easy but the nearest approach to the truth that was ever reached was that a small outbreak of meningitis among Greek Cypriots had now spread to 30 or 40 of their Turkish neighbours and had been positively identified as being due to $N$ meningitidis by the Turkish Hospital in Nicosia. This Hospital had no facilities for typing the organism and no transport medium for sending it elsewhere, so following an appeal to UN HQ the Medical Staff obtained transport media from the Greek Hospital, collected the culture from the Turks and had it typed by the Greeks. In the meantime the Turkish Administration had appealed to WHO through the UN High Commissioner for Refugees for help; to everyone's surprise he received a consignment of "Meningococcal Lyophilised Polysaccharide Vaccine Subgroup A" which was of course almost if not totally ineffective since the responsible organism turned out to be Subgroup B.

This was the first time that the two sides' Health Administrations had cooperated, with CMO UNFICYP as a go-between. There were no telephones across the cease-fire line, nor indeed any means of communication except via the UN. It is also, for the author at any rate, memorable by being the first time he was taken prisoner; he and his driver spent some uncongenial hours surrounded by armed and unfriendly Turkish soldier who had been inadequately informed of their non $\mathbb{8}$ belligerent status and not at all of their errand of mercy,

\section{The Cease-fire Line and No-man's-Land}

The Cease-fire Line marched over 100 miles througt many sorts of terrain: dusty plains, fertile and heavil irrigated farmland, scrub, rocky hills, forests, stream: and standing water, towns and villages and metropolitar믄 Nicosia itself. The width of no-man's-land varied fron? about six metres to several kilometres, and nothing in i尺 had received attention from any Public Health agencis except dogs and cats, and crows and magpies.

\section{Malaria}

The last case of indigenous malaria was reported ios 1949 and in 1959 WHO pronounced the island free. Bu@ freedom had to be fought for, as the following 196\% quotation points out:

\section{"Malaria Maintenance Service}

No other activity of the public health administrationi

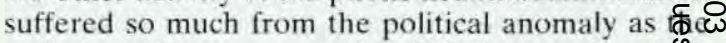
malaria maintenance service. Whole areas in whith access could not be made available remained unchecked, with the result that breeding Anopheles was allowed to proceed. It is fortuna@ however, that in spite of this unhappy state of aff no indigenous case of malaria was reported.

This happening justified the fears expressed lome ago, that although anopheline mosquitos may 8 eradicated from a country, this result could be of o temporary value unless a vigilant service is institutrots to prevent the restablishment of transmission. Such is service was indeed instituted in Cyprus soon after the successful conclusion of the Anopheles eradication $\mathbb{Q}$ campaign.

The main functions of this service are the constan checking of breeding places, residual spraying of suspicious shelters, a vigilant watch on all incomines vessels and aircraft and the disinsectisation of these vessels and aircraft.

\section{$3,424,286$ units were checked for larvae \\ 763,264 shelters were checked for adult mosquitoes 623,840 shelters were sprayed with insecticides \\ 173 units were found positive for larvae and 15 shelters were found positive for adults.}

All positive units were found near the Turkisho controlled areas where enormous difficulties were encountered by the workers and inspectors."

These words are taken verbatim from the Annual Report of the Department of Medical Services for $1965^{2}$ and were again repeated verbatim in that for $1966 \sqrt{\mathrm{N}}$ though by now the number of positive units had droppec ? to 20. It was abundantly clear that following an exceptionally wet spring a return to 1965 conditions, atê 
any rate in No-man's-Land, could confidently be expected. Many mainland Turkish soldiers come from areas where malaria is endemic and the implications of this, with the anticipated anophelism, were as unpleasant as they were obvious.

Under the auspices of the Chicf of Mission of the UN High Commission for Refugees, the CMO and FHI held a meeting at the Ledra Palace Hotel attended by the Greek and Turkish MOHs and Chief Health Inspectors. The Greek Cypriot CHI was man of sterling worth. His records were perfect (the Turks had virtually none at that time), and his drive was such that in a private session with his Turkish opposite number he very soon cajoled, bribed or bludgeoned him into accepting his very comprehensive and detailed plan in toto. Later on, one of the Turkish architects of the original eradication scheme made his advice available.

Anti-malarial work soon began on the Pedieas River in Nicosia under UN armed escort, and a regular 14 day cycle of spraying started along the whole Cease-fire Line on 6 May.

A small but significant redress of balance in the matter of harassment of Public Health personnel took place in connection with this anti-malarial work. A platoon of Hellenic Army paratroopers took and held the CMO and his driver prisoner for some hours, being deeply suspicious of their use of a marked map in the neighbourhood of one of their camps. This made the score one-all.

\section{Metropolitan Sanitation - "The Green Line"}

"The Green Line" is the name given to the border between Greek Nicosia and the Turkish sector, and derives its name from the line drawn in chinagraph across a map by a British Commanding Officer charged with the early peacekeeping in 1963 . It changed its course a little during the fighting of 1974 but in the most congested area of Nicosia it was still represented by a no-man's-land one narrow street in width with a swathe of deserted property either side, each perhaps one or two properties deep. Behind that the bustle of everyday life went on, uninhibited by thought or even awareness of the epidemic potential of a couple of miles of hastily deserted flats, houses and shops, abandoned with meals on the table and food in the powerless refrigerators, fought through by soldiers with loose bowels and declaring its offence to eye and nostril alike.

Under the direction of the Canadian Commander of this sector, local agreement was obtained for this area to be cleansed by the two factions under the general direction of the FHI. This, and dessication by the summer sun later on, removed the threat of a plague of flies and its consequences. Fortunately at no time did the main water supply appear to be in jeopardy.

\section{Hydatid Disease}

Although measures for controlling this disease are relatively straightforward, it has always been endemic in

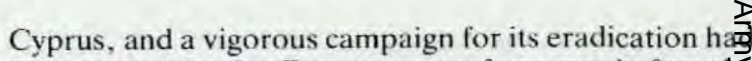
been started by the Government a few years before the coup. Its expressed aims were:

a. Control of abattoirs and slaughtering.

b. Denial of uncooked offal to dogs.

c. Control of stray dogs.

d. Health Education.

Not surprisingly this campaign became a casualty of wate but the need for it remained. Packs of stray an abandoned dogs were to be seen ranging the pla⿳亠丷厂 between Nicosia and Kyrenia; flocks straying across th frontier and subsequently repossessed after UN protegt were always smaller when returned than when capture $\mathbb{p}_{\text {f }}$ and the occasional glimpse of roadside butchery that or $\vec{Q}$ caught suggested that among an army of 40,000 Turks there might be enough uncontrolled slaughter aw butchery to put the epidemiological clock back. T/ dangers of inattention to the matter were spelled og very plainly to the Turkish Cypriot Health Administration and the Turkish Army Liaison Staff, but of coursecis is impossible to comment on how successful were ang efforts they may have made to control the disease.

\section{Humanitarian Medical Work}

Following the cease-fire, medical teams from International Committee of the Red Cross (IC\&) visited Greek Cypriots north of the Line and Turgign Cypriots south of it, and arranged the removal acrosotre Line of the aged, infirm and at times acutely ill. Nei side was disposed to allow their civilian prisoners $10 \mathrm{e}$ taken to their own compatriots without an impatig medical recommendation being made.

As time went on the ICRC ran its medical operati down, and by late spring 1975 it had virtually ceaseo. The result of this was that unsurrendered Turkiof Cypriot villages had to be visited by an UNFICYP M not only when an emergency arose, or was supposed have arisen, but also whenever a case was put to the Greek Cypriot administration to allow a Turki-

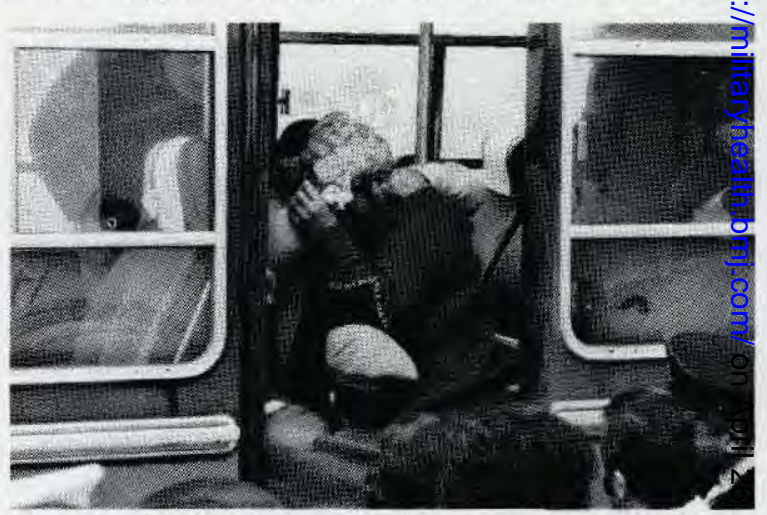

Plate 1 An elderly Turk being moved to the North UNFICYPRCT.

\section{4}


Cypriot to join his compatriots. Although the number of cases seen was not large, the vile condition of the tracks to most of the villages meant that a visit to them by Landrover could take up to five hours.

In August the Greek Cypriot Government decided to send all the Turkish Cypriots to the North. The transfer was of course carried out by the Force through Nicosia with medical cover thereafter being provided by the Turkish Red Crescent. (Plate 1.)

\section{Military Medical Miscellania}

No mention is made in this paper of the day to day problems of health, disease and injury to members of the Force: not that these were trivial problems but they were much the same as those of any force on active service, and as such have been adequately recorded in the literature. What was different about UNFICYP was the variety of the work; 1975 was never dull, the pattern of need and response was constantly changing. Two of the more bizarre incidents are mentioned below.

\section{The Women's Walk Home}

Following a large international publicity and propaganda campaign an estimated 15,000 women took part in a march to the Cease Fire Line just south of the vacated Greek town of Varosha (the holiday resort of Famagusta) to signify their protest against being denied access to their homes. Most were Greek Cypriots but there were many representatives of other nations in the company. No-one knew what to expect: the area was thickly mined and the safe road fairly narrow. The more fanciful had visions of mass hysteria at best and mass immolation at worst and UNFICYP decided to take no chances and set up two comprehensive Dressing Stations. In the event the demonstrators were wellorganised and dignified and the British/Austrian Station only dispensed one piece of sticking plaster and two aspirins all day. (Plate 2.)

\section{Allegations of Brutality}

Not only flocks strayed across the line; shepherds strayed as well and were apt to receive rough justice from their captors. On repatriation these men had to be examined by an UNFICYP MO in order to prevent accusations becoming too wild. This type of medical examination for this cause is of course common enough in all types of medical practice. What gave this an outré quality on occasion was that the request for an examination came from the Leader of the House of

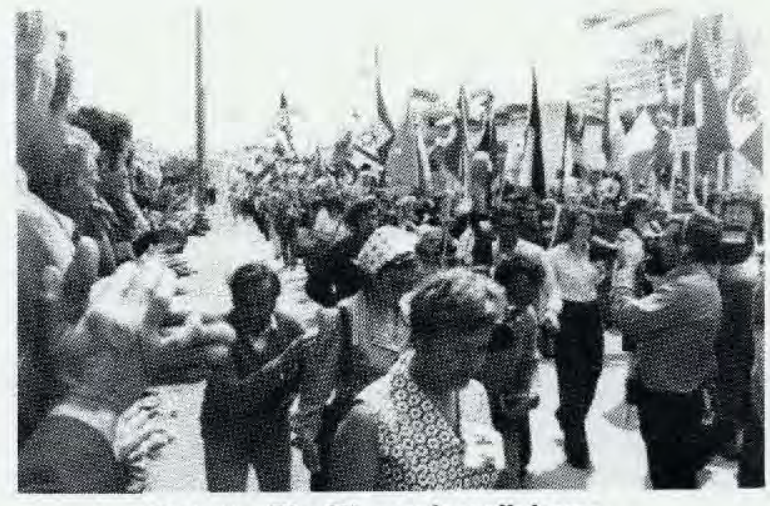

Plate 2 The Women's walk home.

Representatives himself and that the CMO was expected to see the complainant in his office at the House.

\section{Conclusions}

The British Army has a considerable experience o뉴 keeping the peace; although part of its burden has nows been taken up by other countries with professionally ב neutral armies it would be unwise to think that smallo scale military activities such as UNFICYP will never come our way again. Being the $\mathrm{CMO}$ of such a forced presented few difficulties to a RAMC officer of the olfo school, trained in Army Health and with a proper $\overrightarrow{0}$ respect for Tropical Hygiene. As Blewett ${ }^{4}$ hag̊ ơ emphasised, recent events in Rhodesia have taught us yet again that some familiarity with Tropical Medicine and Hygiene is a necessary part of an Army doctor's knowledge, and Hamilton ${ }^{5}$ has also made this point in the Journal of the RAMC. Training as a Community Physician may be a most useful discipline for an Army doctor but it is not in itself sufficient if that doctor has to practice Intercommunity Medicine.

\section{REFERENCES}

1. Tremayne, Penelope, "Below the Tide", (Hutchinson 1958) page 63.

2. Government of Cyprus. Reports of the Department of Medical Services 1965.

3. Government of Cyprus. Reports of the Department of Medical Services 1966.

4. BLEWETT R S. Lecture at RAM College 1980.

5. Hamilton D. Diploma in Tropical Medicine and Hygiene. I R Army Med Corps 1980. 126: 143-4. 